\title{
PENERAPAN METODE SIMPLE ADDITIVE WEIGHTING (SAW) DALAM PEMILIHAN SMARTPHONE ANDROID TERBAIK
}

\author{
Ika Mei Lina ${ }^{1}$, Gilang Ryan Fernandes ${ }^{2}$ \\ ${ }^{1,2}$ Universitas Indraprasta PGRI \\ Jl. Raya Tengah No. 80, Kel. Gedong, Kec. Pasar Rebo, Jakarta Timur 13760 \\ 1ikameilina.24@gmail.com, ${ }^{2}$ gilang.fernandes@gmail.com
}

\begin{abstract}
ABSTRAK
Banyak perusahaan berlomba - lomba menciptakan produk smartphone dengan berbagai jenis, harga, dan fiturfitur menarik didalamnya. Banyaknya pilihan yang ditawarkan membuat konsumen kesulitan dalam mencari smartphone yang sesuai dengan keinginan, sehingga konsumen harus bersusah payah melakukan survei apabila ingin membeli smartphone. Penulis bertujuan membuat sistem pemilihan smartphone terbaik sebagai solusi untuk memudahkan konsumen sebelum membeli smartphone. Metode yang penulis gunakan dalam penelitian ini adalah metode Simple Additive Weighting (SAW), yaitu sebuah metode penjumlahan terbobot dengan mencari rating tiap alternatif yang ada melalui perhitungan berdasarkan bobot kriteria tertentu. Hasil yang diperoleh dalam penelitian ini yaitu menempatkan alternatif A8 sebagai nilai tertinggi dengan hasil nilai 0.982428 , yang berarti alternatif A8 sebagai smartphone terbaik dalam penelitian ini.
\end{abstract}

Kata Kunci: Simple Additive Weighting (SAW), Smartphone, Sistem Pengambilan Keputusan, Android, Java

\begin{abstract}
Many companies are competing to create smartphone products with various types, prices, and interesting features in them. The many choices offered make it difficult for consumers to find a smartphone that suits their wishes, so consumers have to take pains to conduct surveys if they want to buy a smartphone. The author aims to make the best smartphone selection system as a solution to make it easier for consumers before buying a smartphone. The method that the author uses in this study is the Simple Additive Weighting (SAW) method, which is a weighted addition method by finding the rating of each alternative that exists through calculations based on the weight of certain criteria. The results obtained in this study are placing the A8 alternative as the highest value with a value of 0.982428, which means that the A8 alternative is the best smartphone in this study.
\end{abstract}

Key Word: Simple Additive Weighting (SAW), Smartphone, Decision Support System, Android, Java

\section{PENDAHULUAN}

Seiring berkembangnya zaman, berkembang juga kebutuhan - kebutuhan manusia khususnya dibidang teknologi. Salah satu kebutuhan penting manusia saat ini yaitu penggunaan smartphone. Smartphone merupakan telepon genggam yang memiliki fitur canggih menyerupai computer (Daeng et al., 2017). Smartphone bukanlah telepon yang hanya digunakan untuk bekomunikasi maupun SMS melainkan memiliki berbagai teknologi dan aplikasi yang dapat memudahkan pengguna dalam berbagai kebutuhan (Dimas et al., 2017). Fitur canggih dalam smartphone memudahkan pekerjaan serta mendukung gaya hidup sehari - hari.

Banyak perusahaan kini berlomba - lomba menciptakan produk smartphone dengan berbagai jenis, harga, dan fitur - fitur

menarik didalamnya. Banyaknya pilihan yang ditawarkan dengan fitur dan harga yang cenderung tidak jauh berbeda antara satu dengan lainnya membuat konsumen kesulitan dalam mencari smartphone yang sesuai dengan keinginan dan kebutuhan. Hal ini menyebabkan konsumen harus bersusah payah mengumpulkan informasi dan melakukan survei apabila ingin membeli smartphone. Smartphone sendiri menggunakan operasi sistem yang beragam, salah satunya adalah Android. Android merupakan sebuah sistem operasi bebasis linux untuk perangkat mobile yang terdapat didalamnya aplikasi, middleware dan sistem operasi itu sendiri (Putra et al., 2016).

Berdasarkan permasalahan tersebut, maka penulis bertujuan membuat sistem pemilihan smartphone yang berbasis android menggunakan metode Simple Additive Weighting (SAW) sebagai solusi untuk memudahkan konsumen dalam 
menentukan smartphone terbaik dengan lebih efekif dan efisien, khususnya dalam segi waktu dan tenaga. Untuk mendukung pemecahan masalah agar ter-update sesuai kebutuhan konsumen terkini, penulis menggunakan data smartphone terbaru sebagai objek yang akan diaplikasikan ke dalam sistem pemilihan smartphone android terbaik dengan menggunakan metode Simple Additive Weighting (SAW). Menurut Fishburn dan Mac Crimmon dalam Munthe dikemukakan bahwa metode SAW dikenal juga dengan metode penjumlahan terbobot (Munthe \& Ginting, 2013). Hal tersebut dikarenakan pada penerapannya diperlukan proses pencarian penjumlahan terbobot dari tiap kriteria pada masing - masing atribut yang dimiliki oleh alternatif.

Penulis memilih metode SAW sebagai solusi dalam pemecahan masalah pada penelitian ini karena metode SAW dapat menyelesaikan masalah pengambilan keputusan secara praktis dan efektif untuk membantu konsumen menentukan pilihan terhadap smartphone yang akan dibeli. Selain itu, diharapkan juga agar sistem ini dapat digunakan menjadi salah satu masukkan pendukung sebelum konsumen memutuskan untuk membeli smartphone dengan bermacam kriteria yang ada.

\section{METODE PENELITIAN}

Sistem pemilihan smartphone android terbaik ini termasuk dalam kategori penelitian terapan (applied research). Penelitian terapan dilakukan dengan menerapkan, menguji dan mengevaluasi suatu teori guna pemecahan masalah yang bertujuan memberikan solusi secara praktis (Sugiyono, 2012).

Sedangkan metode penelitian yang penulis gunakan dalam penelitian ini yaitu metode kuantitatif. Metode kuantitatif menjelaskan bagaimana variabel yang satu berpengaruh terhadap variabel yang lainnya (Creswell, 2012).

\section{Metode SAW}

Konsep dasar dari metode SAW yaitu mencari rating tiap alternatif yang ada dengan perhitungan berdasarkan bobot kriteria tertentu. Dalam prosesnya melibatkan penyelesaian berupa normalisasi matriks kedalam suatu skala tertentu yang dibandingkan dengan semua rating alternatif (Eniyati, 2011).

Berikut langkah - langkah penyelesaian metode SAW :

1. Menentukan kriteria - kriteria sebagai indikator penentu dalam pengambilan keputusan.

2. Menentukan rating kecocokan tiap alternatif pada setiap kriteria yang sudah ditentukan.

3. Membuat matriks keputusan berdasarkan kriteria.

4. Melakukan normalisasi matriks menggunakan rumus persamaan berikut :

$$
\mathrm{Rij}= \begin{cases}\frac{x_{i j}}{\operatorname{Max}_{i} X_{i j}} & \text { (Jika j adalah atribut } \\ \frac{\operatorname{Min}_{i j} X_{i j}}{x_{i j}} & \text { (Jika j adalah atribut }\end{cases}
$$

Keterangan :

$\mathrm{R}_{\mathrm{ij}}=$ normalisasi matriks

Max $_{\mathrm{ij}}=$ nilai maksimum baris \& kolom

$\operatorname{Min}_{\mathrm{ij}}=$ nilai minimum baris \& kolom

$\mathrm{X}_{\mathrm{ij}}=$ baris dan kolom matriks

5. Memperoleh hasil akhir dari proses perankingan dengan rumus berikut :

$$
V_{i}=\sum_{j=i}^{n} w_{j} r_{i j}
$$

Keterangan :

$\mathrm{V}_{\mathrm{i}}=$ nilai akhir alternatif

$\mathrm{W}_{\mathrm{j}}=$ bobot yang telah ditentukan

$\mathrm{R}_{\mathrm{ij}}=$ normalisasi matriks

\section{HASIL DAN PEMBAHASAN}

Data yang digunakan pada penerapan metode SAW ini yaitu sepuluh smartphone yang memiliki banyak peminat dengan range harga antara 3.000.000 rupiah sampai dengan 4.000.000 rupiah sebagai alternatif yang tersaji dalam struktur hierarki berikut:

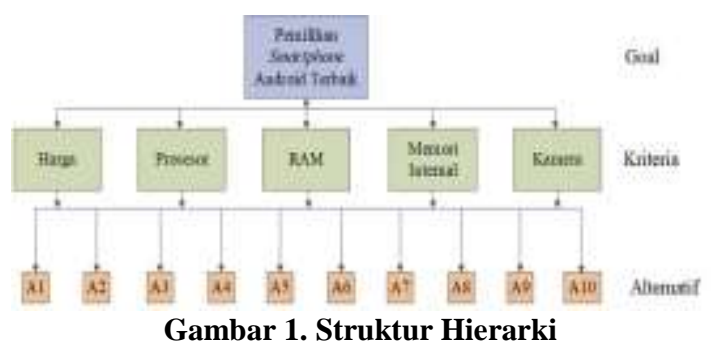


Dalam gambar tersebut terdapat lima kriteria dan sepuluh alternatif dengan keterangan sebagai berikut :
A1 :Realme 8
A2 :Poco X3 Pro
A3 :Redmi Note 10 Pro
A4 :Vivo V21
A5 :Oppo A74
A6 : Samsung Galaxy A22
A7 : Poco X3 NFC
A8 : Realme 8 Pro
A9 : Samsung Galaxy A32
A10 : Oppo Reno5 F

Dalam proses pemilihan kesepuluh smartphone yang menjadi alternaif dalam penelitian ini, dibutuhkan adanya kriteria kriteria sebagai bahan pertimbangan dan perhitungan. Adapun data kriteria - kriteria tersebut tersaji dalam tabel berikut :

Tabel 1. Data Kriteria

\begin{tabular}{llll}
\hline Var & Nama Kriteria & $\begin{array}{l}\text { Benefit } \\
\text { Cost }\end{array}$ & $\begin{array}{l}\text { Nilai } \\
\text { Bobot }\end{array}$ \\
\hline C1 & Harga & Cost & 10 \\
\hline C2 & Prosesor & Benefit & 30 \\
\hline C3 & RAM & Benefit & 30 \\
\hline C4 & Memori Internal & Benefit & 20 \\
\hline C5 & Kamera & Benefit & 10 \\
\hline
\end{tabular}

Pada tabel tersebut terdapat lima kriteria dengan nilai bobot masing - masing sesuai tingkat kepentingan kriteria. Dalam metode SAW dikenal adanya dua atribut kriteria, yaitu benefit dan cost. Perbedaan yang paling mendasar diantara keduanya yaitu dalam pemilihan kriteria untuk perhitungan dalam pengambilan keputusan (Sonata, 2016).

Tabel 2. Data Alternatif dan Data Kriteria

\begin{tabular}{|c|c|c|c|c|c|c|}
\hline Var & $\begin{array}{c}\text { Nama } \\
\text { Alternatif }\end{array}$ & Harga & Processor & $\begin{array}{c}\text { RA } \\
\mathbf{M} \\
(\mathbf{G B})\end{array}$ & $\begin{array}{r}\text { Memol } \\
\text { Intern: } \\
\text { (GB) }\end{array}$ & $\begin{array}{l}\text { iKame } \\
\text { Ira } \\
\text { (MP) }\end{array}$ \\
\hline A1 & $\begin{array}{l}\text { Realme } \\
8\end{array}$ & 3.264 .000 & Helio & 8 & 128 & 64 \\
\hline A2 & $\begin{array}{l}\text { Poco } \\
\text { X3 Pro }\end{array}$ & 3.349 .000 & $\begin{array}{l}\text { Snapdr } \\
\text { agon }\end{array}$ & 6 & 128 & 48 \\
\hline A3 & $\begin{array}{l}\text { Redmi } \\
\text { Note } \\
10 \text { Pro }\end{array}$ & 3.799 .000 & $\begin{array}{l}\text { Snapdr } \\
\text { agon }\end{array}$ & 8 & 128 & $\begin{array}{l}10 \\
8\end{array}$ \\
\hline A4 & $\begin{array}{l}\text { Vivo } \\
\text { V21 }\end{array}$ & 3.874 .000 & $\begin{array}{l}\text { Snapdr } \\
\text { agon }\end{array}$ & 8 & 128 & 64 \\
\hline A5 & $\begin{array}{l}\text { Oppo } \\
\text { A74 }\end{array}$ & 3.049 .000 & $\begin{array}{l}\text { Snapdr } \\
\text { agon }\end{array}$ & 6 & 128 & 48 \\
\hline A6 & $\begin{array}{l}\text { Samsu } \\
\text { ng } \\
\text { Galaxy } \\
\text { A22 }\end{array}$ & 3.220 .000 & $\begin{array}{l}\text { Dimens } \\
\text { ity }\end{array}$ & 6 & 128 & 48 \\
\hline A7 & $\begin{array}{l}\text { Poco } \\
\text { X3 } \\
\text { NFC }\end{array}$ & 3.199 .000 & $\begin{array}{l}\text { Qualco } \\
\mathrm{mm}\end{array}$ & 8 & 128 & 64 \\
\hline
\end{tabular}

\begin{tabular}{lllllll}
\hline A8 & $\begin{array}{l}\text { Realme } \\
\text { 8 Pro }\end{array}$ & 3.699 .000 & $\begin{array}{l}\text { Snapdr } \\
\text { agon }\end{array}$ & 8 & 128 & $\begin{array}{l}10 \\
8\end{array}$ \\
\hline A9 & Samsu & 3.699 .000 & $\begin{array}{l}\text { Dimens } \\
\text { ity }\end{array}$ & 8 & 128 & 48 \\
& ng & & & & \\
& Galaxy & & & & & \\
\hline A32 & & & & & \\
\hline A10 & Oppo & 3.715 .000 & Helio & 8 & 128 & 48 \\
& Reno5 & & & & & \\
& F & & & & & \\
\hline
\end{tabular}

Tabel di atas berisi data - data dari keseluruhan alternatif yang ada beserta kriteria yang belum diproses dengan perhitungan metode SAW.

Tabel 3. Skala Nilai Kriteria Prosesor

\begin{tabular}{cc}
\hline Prosesor & Nilai \\
\hline Helio & 1 \\
\hline Dimensity & 2 \\
\hline Qualcomm & 3 \\
Snapdragon & 4 \\
\hline
\end{tabular}

Tabel di atas berisi nilai data sub-kriteria prosesor yang sudah diubah ke dalam nilai skala 1 sampai dengan 4. Kriteria prosesor termasuk dalam kriteria benefit, sehingga semakin besar nilai skala semakin tinggi nilai atribut dari kriteria tersebut.

Tabel 4. Matriks Nilai Alternatif Setiap Kriteria

\begin{tabular}{cccccc}
\hline & C1 & C2 & C3 & C4 & C5 \\
\hline A1 & 3.264 .000 & 1 & 8 & 128 & 64 \\
\hline $\mathbf{A 2}$ & 3.349 .000 & 4 & 6 & 128 & 48 \\
\hline $\mathbf{A 3}$ & 3.799 .000 & 4 & 8 & 128 & 108 \\
\hline $\mathbf{A 4}$ & 3.874 .000 & 4 & 8 & 128 & 64 \\
\hline $\mathbf{A 5}$ & 3.049 .000 & 4 & 6 & 128 & 48 \\
\hline $\mathbf{A 6}$ & 3.220 .000 & 2 & 6 & 128 & 48 \\
\hline $\mathbf{A 7}$ & 3.199 .000 & 3 & 8 & 128 & 64 \\
\hline $\mathbf{A 8}$ & 3.699 .000 & 4 & 8 & 128 & 108 \\
\hline $\mathbf{A 9}$ & 3.699 .000 & 2 & 8 & 128 & 48 \\
\hline $\mathbf{A 1 0}$ & 3.715 .000 & 1 & 8 & 128 & 48 \\
\hline
\end{tabular}

Tabel matriks di atas berisi data dari tiap alternatif dengan kriteria prosesor yang telah diubah sesuai dengan skala yang sudah ditentukan sebelumnya. Adapun kriteria lain tidak diubah ke dalam skala tertentu karena data sudah berupa angka.

Tahap selanjutnya dari metode SAW yaitu melakukan normalisasi dengan rumus :

$$
\mathrm{Rij}= \begin{cases}\frac{x_{i j}}{\operatorname{Max}_{i j}} & \text { (Jika j adalah atribut } \\ \frac{\operatorname{Min}_{i j} X_{i j}}{x_{i j}} & \text { (Jika j adalah atribut } \\ \text { cost })\end{cases}
$$

Setelah dilakukan perhitungan didapatkan hasil matriks normalisasi dari keseluruhan 
alternatif berdasarkan masing - masing kriteria sesuai pada tabel berikut :

Tabel 5. Matriks Normalisasi

\begin{tabular}{cccccc}
\hline & C1 & C2 & C3 & C4 & C5 \\
\hline A1 & 0.934129902 & 0.25 & 1 & 1 & 0.592592593 \\
\hline A2 & 0.910421021 & 1 & 0.75 & 1 & 0.444444444 \\
\hline $\mathbf{A 3}$ & 0.802579626 & 1 & 1 & 1 & 1 \\
\hline $\mathbf{A 4}$ & 0.787041817 & 1 & 1 & 1 & 0.592592593 \\
\hline $\mathbf{A 5}$ & 1 & 1 & 0.75 & 1 & 0.444444444 \\
\hline $\mathbf{A 6}$ & 0.94689441 & 0.5 & 0.75 & 1 & 0.444444444 \\
\hline $\mathbf{A 7}$ & 0.953110347 & 0.75 & 1 & 1 & 0.592592593 \\
\hline $\mathbf{A 8}$ & 0.824276832 & 0.1 & 1 & 1 & 1 \\
\hline A9 & 0.824276832 & 0.5 & 1 & 1 & 0.444444444 \\
\hline A10 & 0.820726783 & 0.25 & 1 & 1 & 0.4444444444 \\
\hline
\end{tabular}

Setelah didapatkan matriks normalisasi, selanjutnya dilakukan perhitungan untuk menentukan hasil perankingan menggunakan rumus :

$$
V_{i}=\sum_{j=i}^{n} w_{j} r_{i j}
$$

Maka didapatkan hasil nilai untuk setiap alternatif yang ada sesuai dengan tabel 6 dibawah. Adapun perankingan diurutkan mulai dari nilai tertingi sampai dengan nilai terendah, dimana alternatif dengan nilai tertinggi adalah alternatif yang terbaik, sedangkan alternatif dengan nilai terendah adalah alternatif yang terburuk. Hasil akhir dari perangkingan keseluruhan alternatif dapat dilihat pada tabel berikut :

Tabel 6. Hasil Ranking

\begin{tabular}{|c|l|c|c|}
\hline Var & \multicolumn{1}{|c|}{$\begin{array}{c}\text { Nama } \\
\text { Alternatif }\end{array}$} & $\begin{array}{c}\text { Hasil Nilai } \\
\text { Alternatif }\end{array}$ & Ranking \\
\hline A1 & Realme 8 & 0.727672 & 8 \\
\hline A2 & Poco X3 Pro & 0.860487 & 6 \\
\hline A3 & $\begin{array}{l}\text { Redmi Note } \\
\text { 10 Pro }\end{array}$ & 0.980258 & 2 \\
\hline A4 & Vivo V21 & 0.937963 & 3 \\
\hline A5 & Oppo A74 & 0.869444 & 5 \\
\hline A6 & $\begin{array}{l}\text { Samsung } \\
\text { Galaxy A22 }\end{array}$ & 0.714134 & 9 \\
\hline A7 & Poco X3 NFC & 0.87957 & 4 \\
\hline A8 & Realme 8 Pro & 0.982428 & 1 \\
\hline A9 & $\begin{array}{l}\text { Samsung } \\
\text { Galaxy A32 }\end{array}$ & 0.776872 & 7 \\
\hline A10 & Oppo Reno5 F & 0.701517 & 10 \\
\hline
\end{tabular}

Adapun langkah-langkah perancangan aplikasi adalah sebagai berikut:

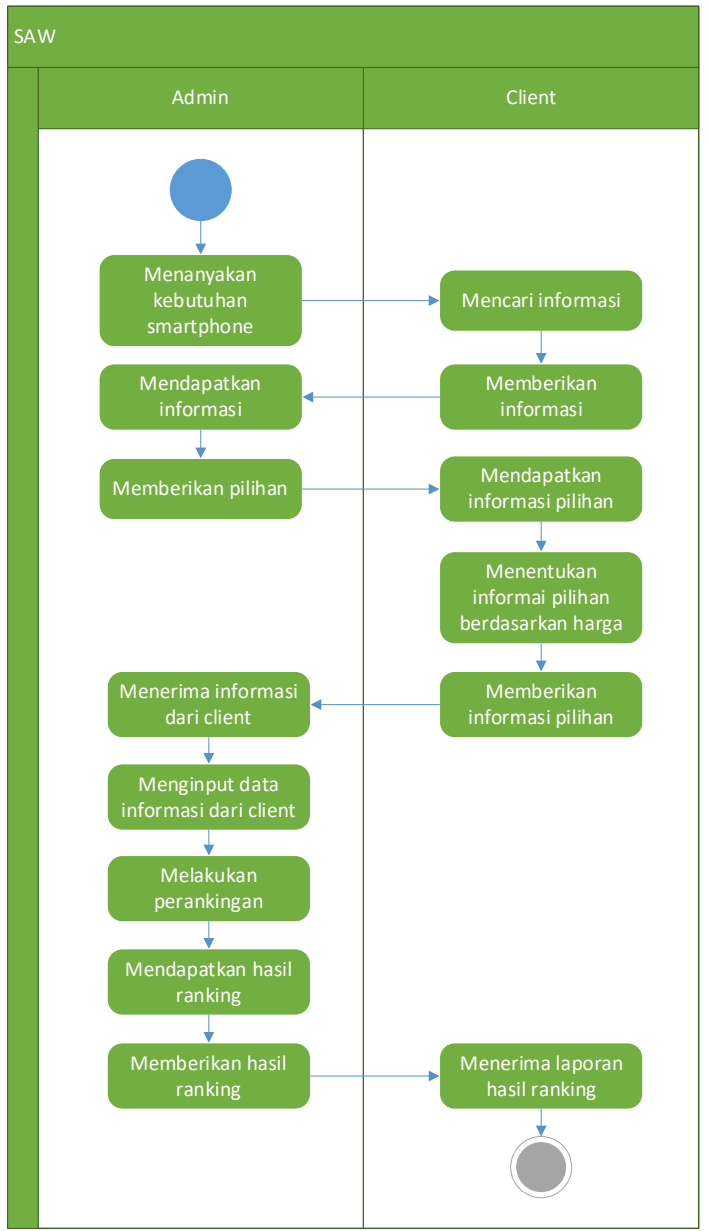

Gambar 2. Activity Diagram

Gambar di atas merupakan activity diagram yang menggambarkan alur proses pendataan untuk aplikasi pemilihan smartphone android terbaik antara admin dan client.

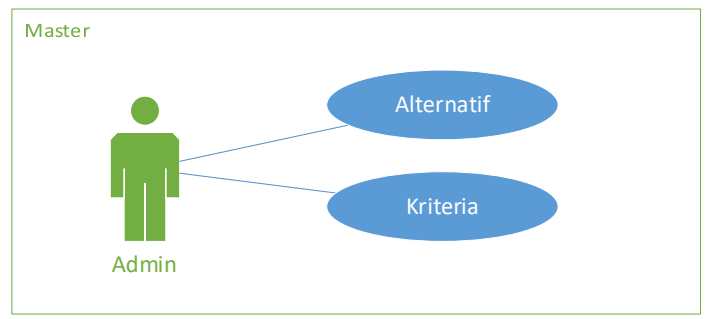

Gambar 3. Usecase Master

Gambar 3 di atas menjelaskan mengenai usecase master dimana admin dapat mengoperasikan form alternatif dan kriteria untuk memanipulasi data. 


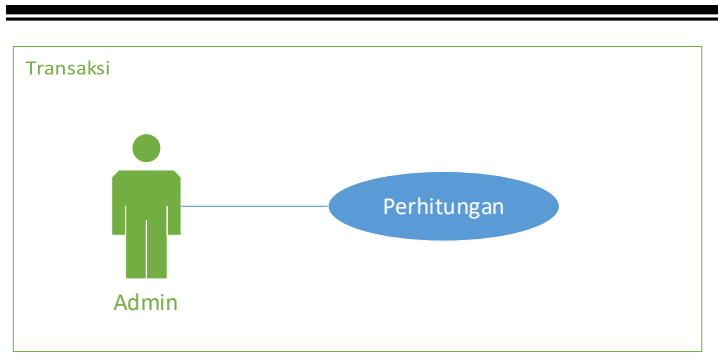

Gambar 4. Usecase Transaksi

Gambar tersebut merupakan usecase transaksi dengan form perhitungan yang dapat diakses oleh admin.

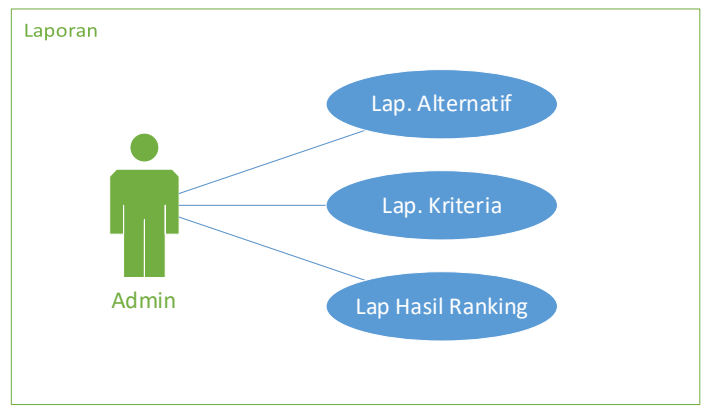

Gambar 5. Usecase Laporan

Gambar di atas menunjukan bahwa terdapat 3 laporan, diantaranya adalah laporan alternatif, laporan kriteria, dan laporan hasil ranking.

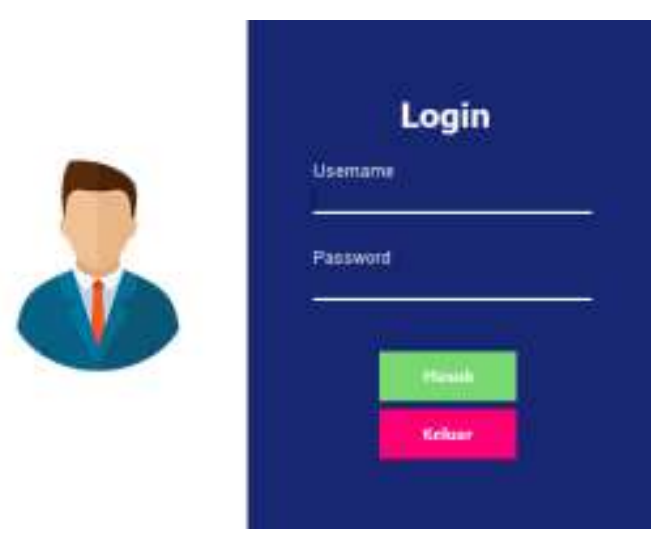

Gambar 6. Form Login

Gambar 1 merupakan form login, dimana form tersebut untuk menvalidasi user yang mengakses aplikasi.

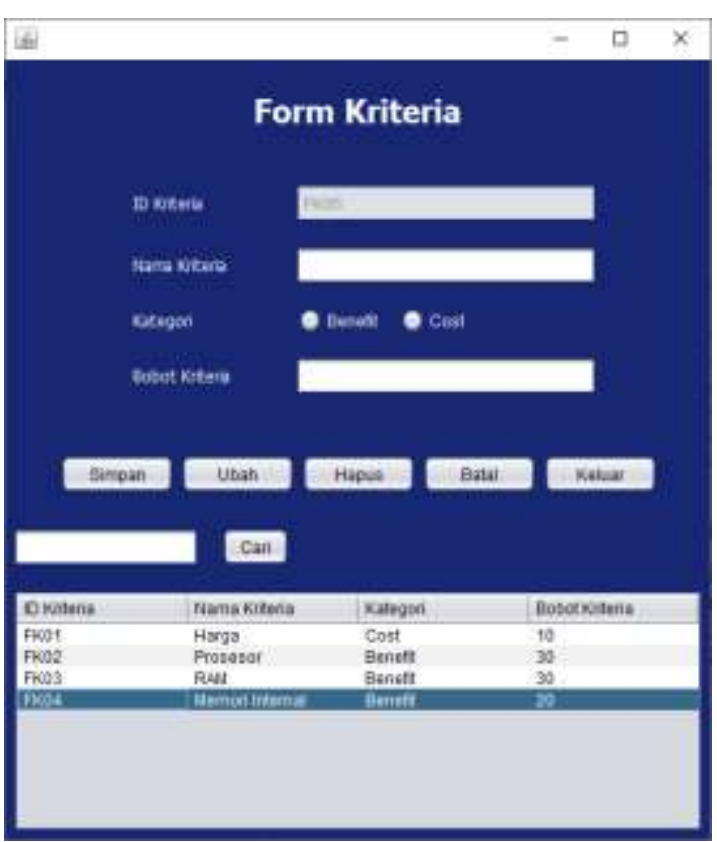

Gambar 7. Form Kriteria

Form Kriteria digunakan untuk menginput data-data kriteria yang berkaitan dengan pemilihan smartphone android terbaik.

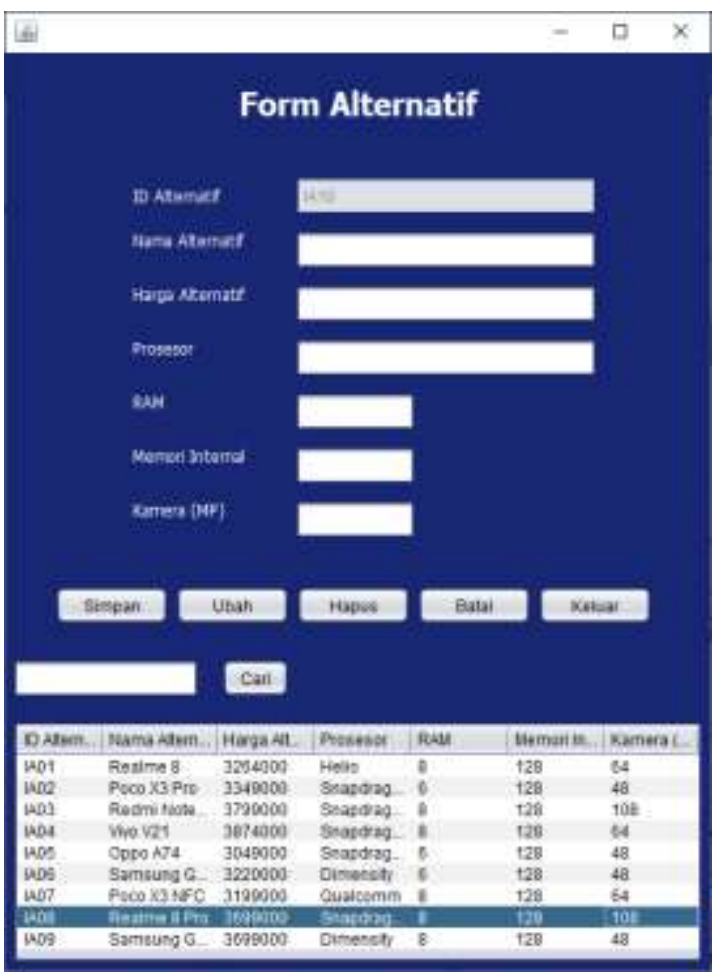

Gambar 8. Form Alternatif

Form diatas digunakan untuk mendata spesifikasi smartphone yang akan dijadikan alternatif dalam penelitian ini. 


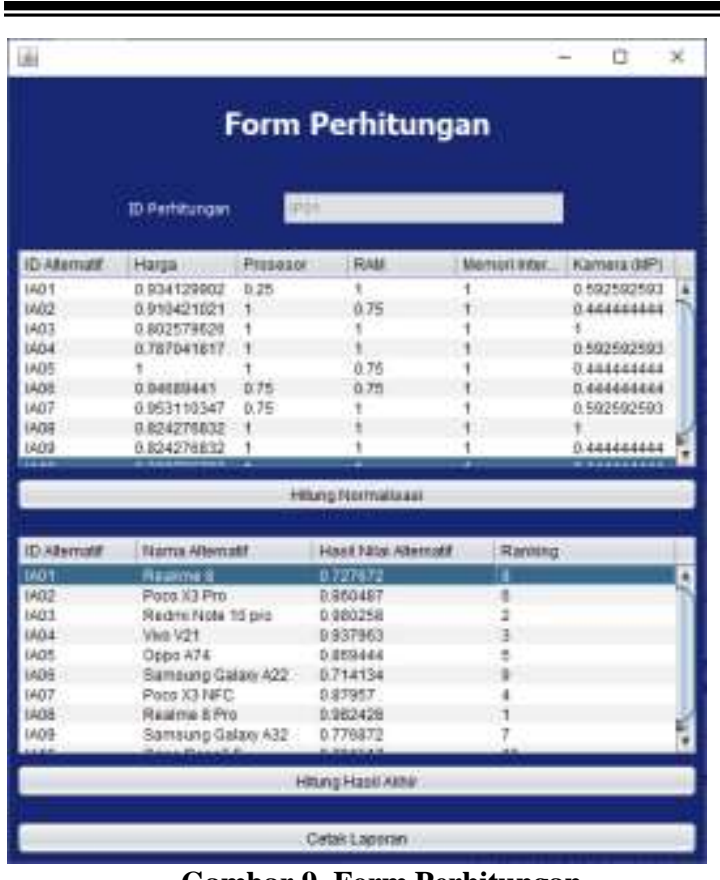

Gambar 9. Form Perhitungan

Form perhitungan diatas merupakan form hasil perhitungan menggunakan metode Simple Additive Weighting (SAW) dimana pada form tersebut terdapat tombol cetak untuk mencetak hasil perhitungan.

\section{SIMPULAN DAN SARAN}

Pada penelitian yang sudah dilakukan, didapat hasil bahwa aplikasi ini dapat membantu masyarakat dalam menentukan smartphone yang sesuai dengan keinginan. Adapun hasil perankingan berdasarkan data alternatif terbaru yang telah di-input kedalam aplikasi menunjukan smartphone android dengan tipe Realme 8 Pro berada diposisi pertama dan menjadi smartphone android terbaik untuk kisaran harga 2 juta sampai 3 juta rupiah sesuai kriteria yang ada. Sementara untuk posisi kedua adalah Redmi Note 10 Pro. Selain itu, metode Simple Additive Weighting (SAW) yang digunakan dalam penelitian ini merupakan metode yang efektif dan bisa menjadi solusi dalam pemilihan smartphone android terbaik sesuai dengan kebutuhan berdasarkan kriteria yang diinginkan.

Adapun saran yang diberikan oleh penulis, sebaiknya untuk pengisian data alternatif dan kriteria pada aplikasi ini menggunakan data yang apple to apple agar mendapatkan hasil yang maksimal.

\section{DAFTAR PUSTAKA}

Creswell, J. W. (2012). Research Design Pendekatan Kualitatif, Kuantitatif, dan Mixed. Pustaka Pelajar.

Daeng, I. T. M., Mewengkang, N. ., \& Kalesaran, E. R. (2017). Penggunaan Smartphone Dalam Menunjang Aktivitas Perkuliahan Oleh Mahasiswa Fispol Unsrat Manado. Acta Diurna, $V I(1), 1-15$.

Dimas, A., Sadewo, B., Widasari, E. R., Muttaqin, A., Informatika, P. S., Komputer, F. I., \& Brawijaya, U. (2017). Perancangan Pengendali Rumah menggunakan Smartphone Android dengan Konektivitas Bluetooth. 1(5), 415-425.

Eniyati, S. (2011). Perancangan Sistem Pendukung Pengambilan Keputusan untuk Penerimaan Beasiswa dengan Metode SAW ( Simple Additive Weighting ). Jurnal Teknologi Informasi DINAMIK, 16(2), 171-177.

Munthe, \& Ginting, H. (2013). Sistem Pendukung Keputusan Penentuan Prioritas Usulan Sertifikasi Guru Dengan Metode Simple Additive Weighting. Pelita Informatika Budi Darma, IV(2), 52-58.

Putra, D. W., Nugroho, A. P., \& Puspitarini, E. W. (2016). Game Edukasi Berbasis Android Sebagai Media Pembelajaran Untuk Anak Usia Dini. 1(1), 46-58.

Sonata, F. (2016). Implementasi Metode Simple Additive Weighting ( SAW ) Dengan Proses Fuzzifikasi Dalam Penilaian Kinerja Dosen. Jurnal Teknologi Informasi Dan Komunikasi, 5(2), 71-80.

Sugiyono. (2012). Metode Penelitian Kuantitatif Kualitatif dan $R \& D$. AlfaBeta. 